\title{
Correlation between indoor and outdoor air
}

\author{
J. A. Radaideh \& Z. Shatnawi \\ Department of Civil and Environment at King Faisal University (KFU), \\ Saudi Arabia
}

\begin{abstract}
Both indoor and outdoor air quality in residential areas of Al Hofuf city/eastern province of Saudi Arabia was studied through a multi-week multiple site measurement and sampling survey. Concentration levels of five criteria air pollutants, including carbon dioxide $\left(\mathrm{CO}_{2}\right)$, carbon monoxide $(\mathrm{CO})$, nitrous dioxide $\left(\mathrm{NO}_{2}\right)$, sulfur dioxide $\left(\mathrm{SO}_{2}\right)$ and total volatile organic compounds (TVOC) were measured and analyzed during the study period from January to May 2014. For this survey, three different location points - including roadside RS, urban UR, and rural RU - were selected. Within each site type, six locations were assigned to carry out air quality measurements and to study varying indoor/outdoor air quality.

Results indicated that a strong correlation between indoor and outdoor air existed. The I/O ratios for the considered criteria pollutants showed that the strongest relationship between indoor and outdoor air was found by carbon dioxide, $\mathrm{CO}_{2}$ in the range of 0.88 , while the lowest is found by both $\mathrm{NO}_{2}$ and $\mathrm{SO}_{2}$ in the range of 0.7 .
\end{abstract}

Keywords: air pollutants, indoor/outdoor air pollution, indoor/outdoor ratio, Saudi Arabia.

\section{Introduction}

Air pollution in Saudi Arabia and in neighboring regions is a major concern for government, health institutions, researchers and public. Sources of air pollution include traffic, industrial plants (from brick making to oil and gas production), power plants, cooking and heating with solid fuels (e.g. coal, wood, crop waste), forest fires and open burning of municipal waste and agricultural residues $[1,2]$.

The biggest reason for ambient air pollution in Saudi Arabia at the moment are emissions from vehicles [6]. Today; traffic pollution is predominant and greatly 
contributes in the urban air quality problems, especially in roads of crowded traffic [9]. Everywhere in the country cars, trucks and other vehicles are used for transportation. Also, there is migration of people from rural areas to crowded cities looking for jobs, services and better living environment. This has also contributed dramatically to the ambient air quality prevalent in major cities across Saudi Arabia.

Higher rates of air pollution are becoming strongly correlated with economic progress and improving style of living. Saudi Arabia's energy consumption has climbed dramatically over the past two decades. In year 1980, the energy consumption was 1.7 quadrillion Btu (quads), and it jumped to 4.6 quads in year 2000. Saudi Arabia consumes about $1.1 \%$ of the world energy consumption. Therefore, Saudi Arabia's carbon emissions from transport sector have jumped in the past 40 years from 3.29 million metric tons in the year 1971 to 104.42 million metric tons in year 2010 .

Air pollution in Saudi Arabia is now recognized as a significant environmental impact of intensive anthropogenic activities.

Several environmentalists in Saudi Arabia are proposing new ideas to find a solution that can help in fighting pollution in air through extensive development of pollution and environment laws. Therefore, special attention to monitoring and reducing such emissions through concerted efforts should be immediately under taken at both national and international levels alike. These conclusions are supported by several investigations [14-18].

This research was carried out to help in assessing the status of indoor and outdoor air pollution in Al Hofuf city/eastern province of Saudi Arabia and to discuss measures on reducing indoor air pollution and the associated health effects on humans and environment.

\section{Methodology}

A comprehensive study is conducted in residential areas of Al Hofuf city/eastern region of Saudi Arabia through a multi-week multiple sites sampling survey. Five of air pollution indicators, together with relevant meteorological parameters were simultaneously monitored for indoor and outdoor within a period of four months. The monitoring of indoor and outdoor air include streets, homes, flats, and restaurants. The particularly important air quality indicators including: total volatile organic compounds (TVOCs), carbon monoxide (CO) and carbon dioxides $\left(\mathrm{CO}_{2}\right)$, which were measured in parts per million (ppm); sulfur dioxide $\left(\mathrm{SO}_{2}\right)$, Nitric Oxide $\mathrm{NO}_{2}$ are measured in $\mu \mathrm{g} / \mathrm{m}^{3}$.

Three site-types - roadside RS, urban UR, and rural RU - were selected for this study to carryout air quality measurements and to assess varying indoor/outdoor air quality. All selected sites are residential areas. At each assigned point three measurements are randomly taken for indoor and three measurements for outdoor air. Roadside sites RS were selected in heavy traffic roads (Riyad road, RS1) and Qayssariah Market, RS2), which have some of the highest traffic flows in AlHofuf downtown. Two urban sites (UR1 and UR2) were selected near (Village Market), which is a rapidly developing area outside the dense populated old city. 
Rural sites (RU1) and (RU2) are selected far away from the roadside and urban areas.

For the measurements the instrument direct Sense IAQ meter, manufacturer Gray Wolf sensing solutions is used.

Average hourly measurements were taken over the sampling period, (January 2014-April 2014). To consider the effect of traffic density on the AQ, the data have been collected over different periods of time. The concentrations of air pollutants were recorded in real time at $20 \mathrm{~min}$ intervals. During the measurements, indoor air is supplied directly from outdoor air, so that air pollutants found in indoor air are resulted from outdoor emissions only.

\section{Results}

\subsection{Assessment of air quality}

The daily range and average concentrations of the measured pollution indicators during the periods of study for all selected locations (RS1, RS2, UR1, UR2, RU1 and RU2) are summarized, simultaneously with the I/O ratios in table 1 . It shows additionally the averages of all min. and max. readings. From this table, it is to predict that each pollutant has almost the same daily fluctuation trend during the time of measurements, and that the lowest concentrations are recorded at the early hours of the day and increase at the end of the day.

\subsection{Analysis of TVOC concentrations}

Table 1 shows that the hourly recorded concentrations of total volatile organic compounds (TVOC) for indoor air at all locations (RS1, RS2, UR1, UR2, RU1 and RU2) ranged between the lowest value of $15.00 \mathrm{ppb}$ and the max. value of 69 $\mathrm{ppb}$. For outdoor air the values fluctuated between 21.0 to $84.0 \mathrm{ppb}$. The overall average of indoor readings equals $27.56 \mathrm{ppb}$ and for all outdoor values $34.16 \mathrm{ppb}$. The $\mathrm{I} / \mathrm{O}$ ratio for all locations ranged from 0.51 to 1.00 with an overall average of 0.8 . In general, it is to notice that values are high at the sites RS1 and RS2 and low at the sites UR1 and UR2.

And because the site RS1 represents a downtown area with crowded traffic, the indoor and outdoor concentrations are close to each other, indicating the strong correlation as shown in figure 1.

\subsection{Analysis of $\mathrm{CO}$ concentrations}

The lowest recorded hourly outdoor carbon monoxide concentration is $1.2 \mathrm{ppm}$ found in the early morning at both sites RS1 and RS2, while the highest recorded concentration of $5.3 \mathrm{ppm}$ is found at sites (UR1 and UR2). The average for all outdoor readings and for all sites is $3.5 \mathrm{ppm}$ and the allover average for indoor readings is $2.13 \mathrm{ppm}$. The $\mathrm{I} / \mathrm{O}$ ratio for all readings ranged from 0.286 to 1.77 with an overall average of 0.65 . 


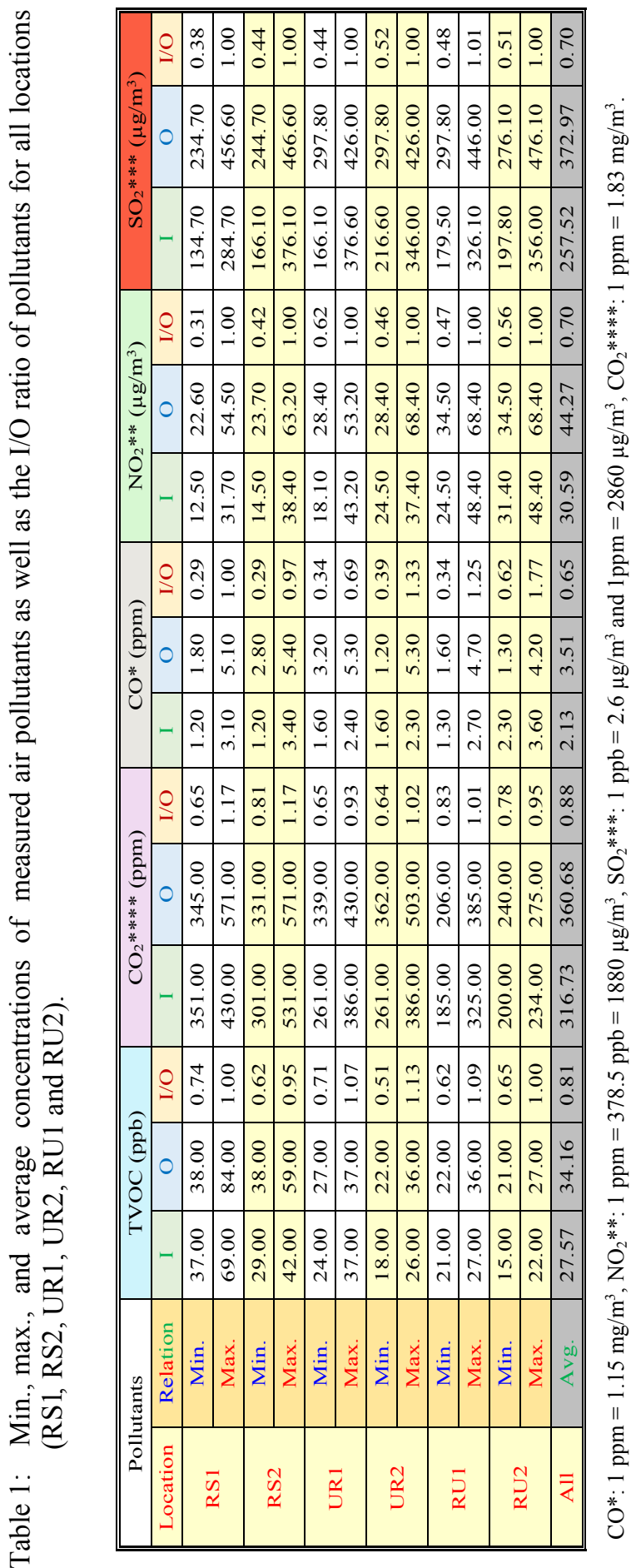




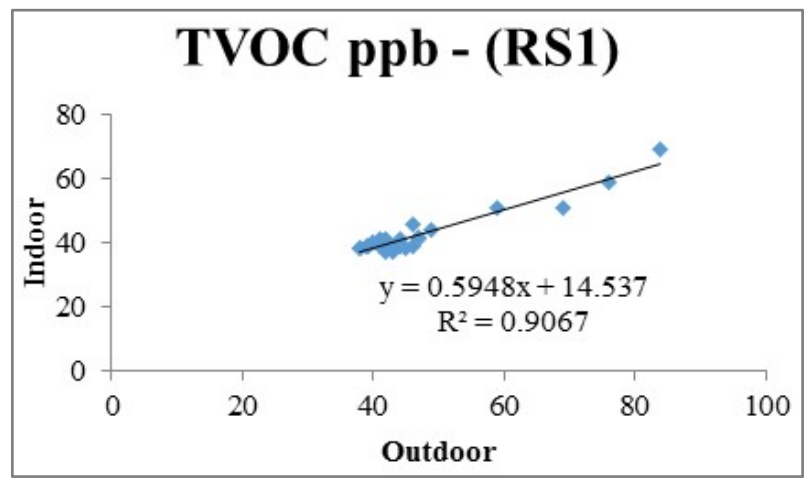

Figure 1: Correlation curve between indoor and outdoor concentrations of TVOC at RS1.

It is clear from the results that all indoor as well outdoor values recorded were below $5.3 \mathrm{ppm}$. Similar values for carbon monoxide I/O ratios are reported in [1921].

Comparing all the recorded measurements with the available standards presented in table 2, It is clear that all concentrations of carbon monoxide for both indoor and outdoor were below the 1-h average standards (ranged between $13 \mathrm{ppm}$ of Alberta guidelines and 35 ppm of both PME standard and NAAQSs, USA).

Figure 2 demonstrates the average $\mathrm{CO}$ concentrations of indoor and outdoor air at both locations RS2. From this figure it is easy to see that the I/O ratio fluctuates between 0.8 to 1.00 , indicating the strong correlation between indoor and outdoor air at both sites.

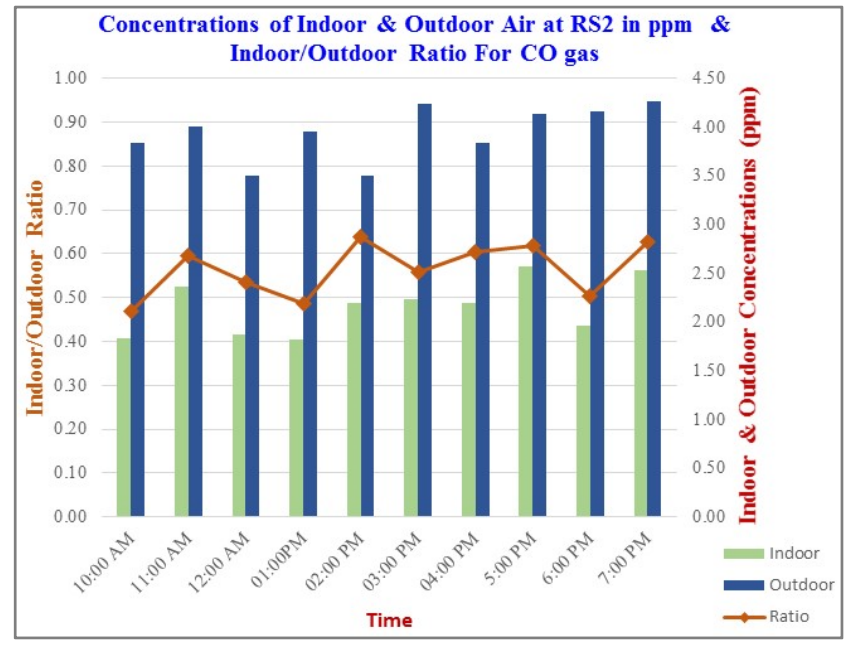

Figure 2: Concentrations of indoor and outdoor in $(\mathrm{ppm})$ and $\mathrm{I} / \mathrm{O}$ ratio for $\mathrm{CO}$ gas at RS2. 
Table 2: Air quality standards in different countries (ppm).

\begin{tabular}{|l|c|c|c|c|}
\hline \multicolumn{1}{|c|}{ Standards } & $\mathbf{C O}$ & $\mathbf{N O}_{2}$ & $\mathbf{O}_{3}$ & $\mathbf{S O}_{2}$ \\
\hline NAAQSs (USA) 1-h average & 35 & 0.246 & & 0.12 \\
\hline NAAQSs (USA) 1-8h average & 9 & & & \\
\hline NAAQSs (USA) 3-h average & & & & 0.5 \\
\hline NAAQSs (USA) 24-h average & & & & 0.14 \\
\hline NAAQSs (USA) annual average & & & & 0.14 \\
\hline $\begin{array}{l}\text { NAAQSs (Canada) } \\
\text { Desirable 1-h average }\end{array}$ & 13.1 & & 0.051 & 0.172 \\
\hline $\begin{array}{l}\text { NAAQSs (Canada) } \\
\text { Desirable 24-h average }\end{array}$ & 30.6 & 0.213 & 0.082 & 0.334 \\
\hline $\begin{array}{l}\text { NAAQSs (Canada) } \\
\text { Acceptable 1-h average }\end{array}$ & & 0.106 & & 0.057 \\
\hline $\begin{array}{l}\text { NAAQSs (Canada) } \\
\text { Acceptable 24-h average }\end{array}$ & 26 & 0.07 & $0.5-0.1$ & 0.13 \\
\hline WHO 1-h average & & & & $0.038-0.058$ \\
\hline WHO 24-h average & 0.14 & & & 0.28 \\
\hline WHO annual average & 0.028 & & & 0.017 \\
\hline EU guidelines 1-h average & 13 & 0.21 & 0.082 & 0.17 \\
\hline EU guidelines 24 h average & & 0.11 & 0.025 & 0.06 \\
\hline Alberta Guidelines 1-h average & 25 & 0.15 & 0.1 & 0.015 \\
\hline Alberta Guidelines 24-h average & 35 & 0.35 & 0.15 & 0.14 \\
\hline NAAQSs (Korea) 1-h average & 0.35 & 0.15 & 0.28 \\
\hline NAAQSs (Korea) 24-h average & & & 0.14 \\
\hline PME (MEPA) 1-h average & 35 & & \\
\hline PME (MEPA) 24-h average & & & \\
\hline
\end{tabular}

\subsection{Analysis of $\mathrm{CO}_{2}$ concentrations}

The recorded concentrations of $\mathrm{CO}_{2}$ indoors and outdoors are laying close together. The indoor concentrations ranged from 200 to $351.0 \mathrm{ppm}$ with an overall average of $316.73 \mathrm{ppm}$, while the outdoor concentrations range from 206 to 571 $\mathrm{ppm}$ with an average of $360.68 \mathrm{ppm}$. The I/Q values range from 0.65 to 1.17 forming an overall average of 0.88 . Figure 3 shows the relationship between indoor and outdoor $\mathrm{CO}_{2}$ concentrations measured at $\mathrm{RS} 2$. The correlation coefficient $\mathrm{R}^{2}$ is found as high as 0.6 . 


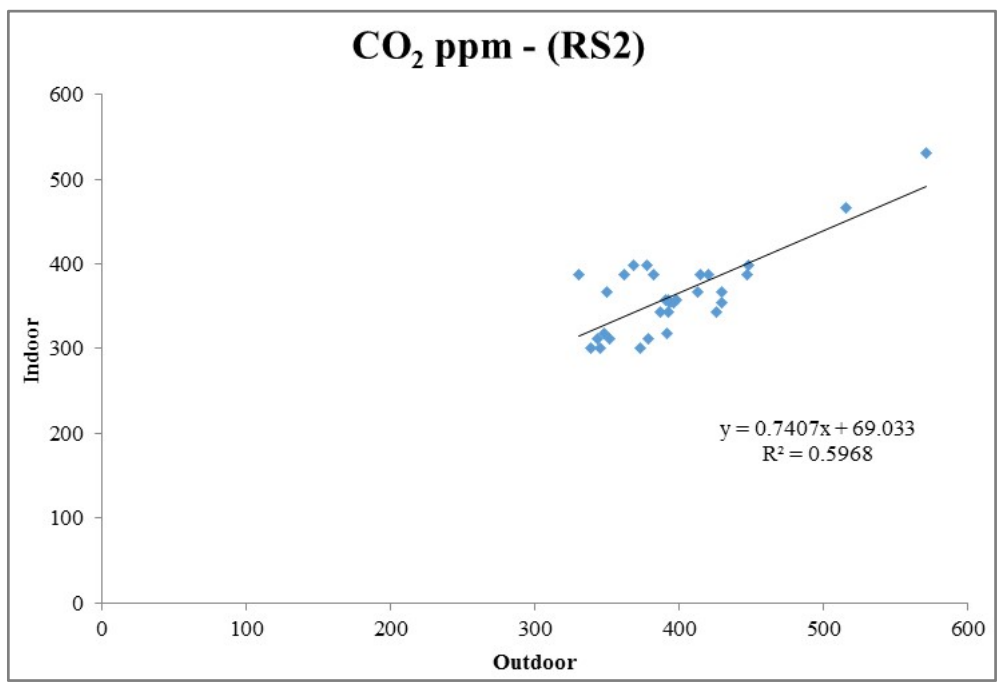

Figure 3: Correlation curve between indoor and outdoor concentrations of $\mathrm{CO}_{2}$ at RS2.

\subsection{Analysis of $\mathrm{NO}_{2}$ concentrations}

The recorded hourly concentrations of nitrogen dioxide, $\mathrm{NO}_{2}$ for outdoor air fluctuated between the lowest value of $\left(22.6 \mu \mathrm{g} / \mathrm{m}^{3}=0.012 \mathrm{ppm}\right)$ is found at RS1 and the highest value $\left(68.4 \mu \mathrm{g} / \mathrm{m}^{3}=0.036 \mathrm{ppm}\right)$ found at the sites UR2, RU1 and RU2. The overall average for outdoor values is $44.7 \mu \mathrm{g} / \mathrm{m}^{3}(0.023 \mathrm{ppm})$. For indoor air concentrations placed between the min. concentration of $12.5 \mu \mathrm{g} / \mathrm{m}^{3}$ $(0.007 \mathrm{ppm})$ measured at RS1 and the maximum concentration of $48.4 \mu \mathrm{g} / \mathrm{m}^{3}$ $(0.045 \mathrm{ppm})$ found at both locations UR1 and UR2, with an overall average of $30.59 \mu \mathrm{g} / \mathrm{m}^{3}(0.016 \mathrm{ppm})$. The $\mathrm{I} / \mathrm{O}$ ratio ranged from 0.306 to 1.00 with an overall average of 0.702. Comparatively, similar values for $\mathrm{NO}_{2} \mathrm{I} / \mathrm{O}$ ratios are reported in previous investigations [19, 22-24].

The recorded concentrations for both outdoor and indoor shows an increasing trend starting with low values in the early hours of the day and increase during the late hours.

Figure 4 presents the correlation coefficient $\mathrm{R}^{2}$ between indoor and outdoor for $\mathrm{NO}_{2}$ is found as much as 0.7631 indicating a strong and positive correlation function.

\subsection{Analysis of $\mathrm{SO}_{2}$ concentrations}

From table 1, it can be seen that the hourly indoor $\mathrm{SO}_{2}$ concentration ranged from $134.7 \mu \mathrm{g} / \mathrm{m}^{3}(0.047 \mathrm{ppm})$ to $284.7 \mu \mathrm{g} / \mathrm{m}^{3}(0.1 \mathrm{ppm})$ with an overall average of $257.51 \mu \mathrm{g} / \mathrm{m}^{3}(0.09 \mathrm{ppm})$ and that the outdoor concentrations ranged from $234.7 \mu \mathrm{g} / \mathrm{m}^{3}(0.08 \mathrm{ppm})$ to $456.6 \mu \mathrm{g} / \mathrm{m}^{3}(0.16 \mathrm{ppm})$ with an overall average of 


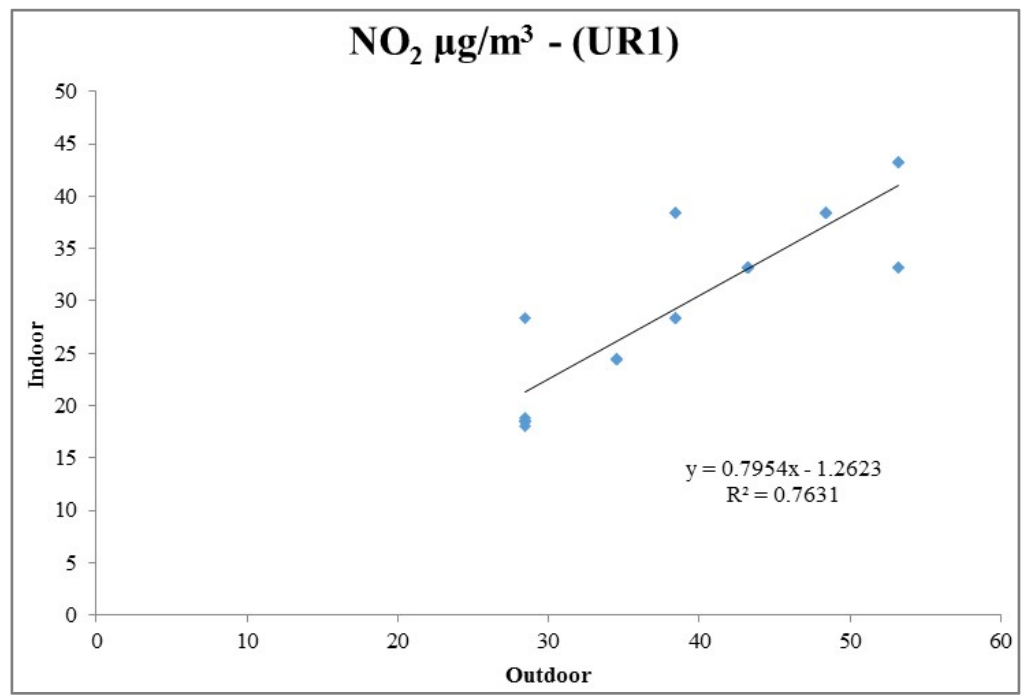

Figure 4: Correlation curve between indoor and outdoor concentrations of $\mathrm{NO}_{2}$ at UR1.

$372.97 \mu \mathrm{g} / \mathrm{m}^{3}(0.13 \mathrm{ppm})$. The $\mathrm{I} / \mathrm{O}$ of all readings ranged from 0.38 to 1.00 with an overall average of 0.696 . It has been noticed that all the recorded results were fluctuating in a narrow range.

Figure 5 shows the correlation function between indoor and outdoor for $\mathrm{SO}_{2}$ with a correlation coefficient $\mathrm{R}^{2}=0.45$.

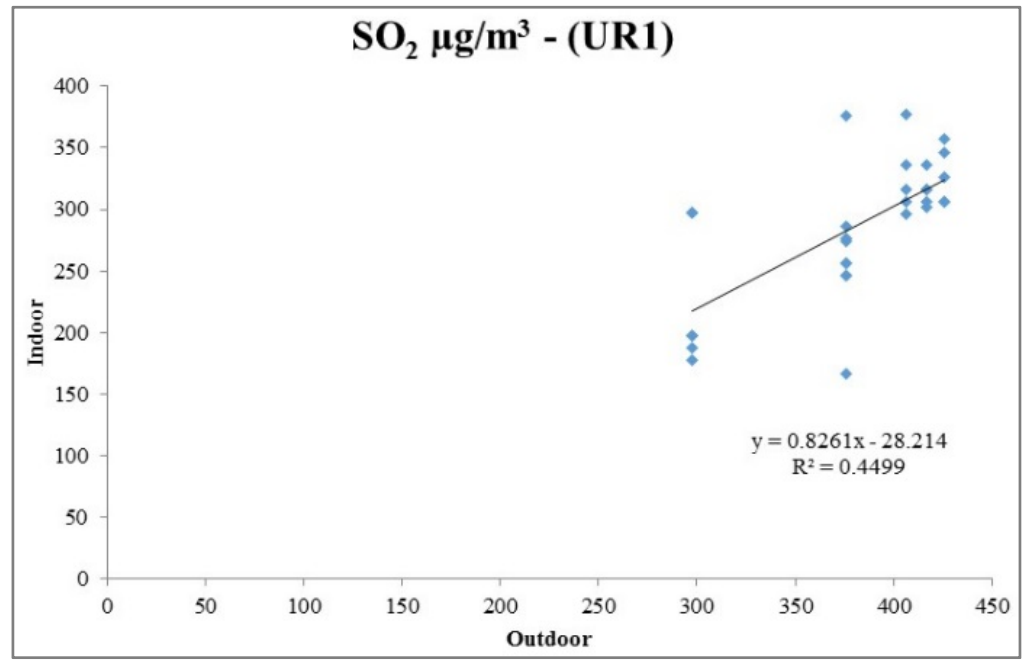

Figure 5: Correlation curve between indoor and outdoor concentrations of $\mathrm{SO}_{2}$ at UR1. 


\section{Conclusion}

Based on the results of measurements and experiments obtained in this study, the following conclusions can be demonstrated:

1. The results of this study have confirmed the importance of ambient air in determining the quality of air indoors and that there is a strong correlation between outdoor and indoor air.

2. Although the existing concentrations for the critical air pollutants in outdoor/indoor air of Al-Hofuf city didn't exceed the allowable limits described in national and international standards, the existing pollution is significant and can't be ignored.

3. The strongest relationship between indoor and outdoor air was found by carbon dioxide, $\mathrm{CO}_{2}$ in the range of 0.88 , while the lowest is found by both $\mathrm{NO}_{2}$ and $\mathrm{SO}_{2}$ in the range of 0.7 .

4. Nitrogen oxides and carbon monoxide concentrations increased at the starting hours of the day, then, they fluctuated within a limited range of concentrations during the remaining hours of the day, but with decreasing trend. The reason of reduction can be attributed to the effect of the meteorological conditions.

5. Sulfur dioxide showed a relatively constant and low concentration.

\section{Acknowledgements}

This work was supported by the project (No. 140205), funded by the scientific research deanship at King Faisal University/KFU. The authors are highly acknowledged and express their gratitude to high support received from the KFU, who provided the necessary financial and technical support for completing this research work.

\section{References}

[1] WHO, Fact sheet No. 313, 2014. Ambient (outdoor) air quality and health. And WHO guidelines for indoor air quality: selected pollutants, 2010. http://www.who.int/mediacentre/factsheets/fs313/en/.

[2] IARC and WHO (World Health Organization) (2013). IARC: Outdoor air pollution a leading environmental cause of cancer deaths. News release, 17 October. http://www.iarc.fr/en/media-centre/pr/2013/pdfs/pr221_E.pdf.

[3] Montgomery D.D., and Kalman D.A. (1989).Indoor/Outdoor air quality. Appl. Ind. Hyg. 4, 17-20.

[4] EPA's Integrated Risk Information System (IRIS). www.epa.gov/iris June 2010.

[5] American Society of Heating, Refrigeration, and Air Conditioning Engineers (ASHARE) standard 62.1 - 2004. Ventilation of acceptable air quality, 2004. 
[6] Abdallah, Kathleen. "Health and Environmental Benefits of Clean Fuels and Vehicles". Keynote presentation. Cairo, Egypt: UN DESA, May 24, 2006.

[7] United Nations Environment Programme, Annual evaluation report/ Evaluation and oversight unit (UNEP, 1999).

[8] US Dept. of energy/ Energy information administration. Overview data for Saudi Arabia, 2013. (www.eia. doe.gov/emeu/cabs/saudenv.html).

[9] Karin B. Yeatts, Mohamed El-Sadig, David Leith, William Kalsbeek, Fatma Al-Maskari, David Couper, William E. Funk, Taoufik Zoubeidi, Ronna L. Chan, Chris B. Trent, Christopher A. Davidson, Maryanne G. Boundy, Maamoon M. Kassab, Mohamed Y. Hasan, Ivan Rusyn, Jacqueline MacDonald Gibson and Andrew F. Olshan. Indoor Air Pollutants and Health in the United Arab Emirates. Environmental Health Perspectives. Volume 120, number 5, May 2012. Environ Health Perspect; DOI:10.1289/ehp.1104090.

[10] PME, Presidency of Meteorology and Environment, Saudi Arabia. General Environmental Regulations and Rules for Implementation. 28 Rajab 1422 H (15 October 2001). www.pme.gov.sa/en/eindex.asp and PME, Kingdom of Saudi Arabia National Environmental Standard. Environmental Standards/ Ambient Air Quality.

[11] Environmental Research and Wildlife Management Agency (ERWMA, 2005). Abu Dhabi air quality monitoring and management project. Air quality in Abu Dhabi. http://www.ead.ae/TacSoft/FileManager/ Newsletter/PDF/AlDhabiEnglish.pdf (accessed March 21, 2008).

[12] Environmental Research and Wildlife Management Agency (ERWMA, 2005). Air quality management in Saudi Arabia http://www.ead.ae/TacSoft/ FileManager/Newsletter/PDF/AlDhabiEnglish.pdf (accessed March 21 2008).

[13] Al-Hesabi, A. "The economic and policy internationalization of externalities from the powerplants as a tool for progressing towards sustainability, the case of Bahrain". Public commission for the Protection of Marine resources, Environment, and Wildlife, Bahrain, 2004.

[14] Hesham A. Al-Jeelani. Air quality assessment at Al-Taneem area in the Holy Makkah City, Saudi Arabia. Environ Monit Assess, DOI 10.1007/s10661-008-0475-3. Received: 30 January 2008/Accepted: 27 June 2008. (C) Springer Science + Business Media B.V. 2008.

[15] Mahmoud F. El-Sharkawy, Mohamed E. H. Noweir. Indoor air quality levels in a University Hospital in the Eastern Province of Saudi Arabia. Journal of Family and Community Medicine, April 2014, Vol 21, Issue 1.

[16] Chaloulakou, A., Mavroidis, I. and Duci, A. (2003). Indoor and outdoor carbon monoxide concentration relationships at different microenvironments in the Athens area. Chemosphere 52 (6), 1007-1019.

[17] Haimour, N.M., Emeish, S., Utilization of date stones for production of activated carbon using phosphoric acid. Waste Management 26 (2006) 651660 . 
[18] Al-Rehaili, A.M. Outdoor-indoor air quality in Riyadh: SO2, NH3, and HCHO. Environ Monit Assess. 2002 Nov. 79(3):287-300.

[19] Crump, D., Dimitroulopoulou, S., Squire, R., Ross, D., Pierce, B., White, M. Brown, V. and Coward, S. (2004). Ventilation and indoor air quality on new homes. In: Proceedings of the 13th World Clean Air and Environmental Protection Congress, 22-27 August 2004, London, UK.

[20] NiRiain, C.M., Mark, D., Davies, M., Harrison, R.M. and Byrne, M.A. (2003). Averaging periods for indoor-outdoor ratios of pollution in naturally ventilated non-domestic buildings near a busy road. Atmospheric Environment 37 (29), 4121-4132.

[21] Dimitroulopoulou, C., Crump, D., Coward, S.K.D., Brown, B., Squire, R., Mann, H., White, M., Pierce, B. and Ross, D. (2005).Ventilation, Air Tightness and Indoor Air Quality in New Homes.BR477, BRE Bookshop, UK, ISBN 1860817408.

[22] Drakou, G., Zerefos, C., Ziomas, I., and Voyatzaki, M. (1998). Measurement and numerical simulations of indoor $\mathrm{O} 3$ and $\mathrm{NO}_{\mathrm{x}}$ in two different cases. Atmospheric Environment 32 (4), 595-610.

[23] Coward, S.K.D. and Ross, D.I. (2001). Nitrogen dioxide and carbon monoxide levels in England. In: Proceedings of Indoor Air '2001, 30 June5 July, Edinburgh, UK.

[24] Kousa, A., Monn, C., Rotko, T., Alm, S., Oglesby and Jantunen, M.J. (2001). Personal exposure to $\mathrm{NO}_{2}$ in the EXPOLIS-study: relation to residential indoor, outdoor and workplace concentrations in Basel, Helsinki and Prague. Atmospheric Environment 35 (20), 3405-3412. 